\title{
Assessment of social and psychological adaptation of foreign students in the conditions of the Metropolitan metropolis
}

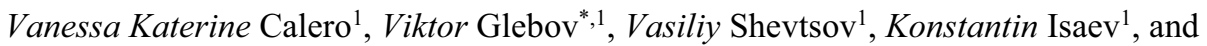 \\ Dilyara Efremova ${ }^{2}$ \\ ${ }^{1}$ Peoples Friendship University of Russia (RUDN University), Miklukho-Maklaya Str., 6, 117198 \\ Moscow, Russia \\ ${ }^{2}$ Vygotsky Institute of Psychology, Russian State University for the Humanities, Miusskaya sq. 6, \\ 125993, Moscow, Russia
}

\begin{abstract}
A sample of 264 practically healthy students from Beijing, Harbin, XI'an, and Moscow (197 Chinese and 67 Russian students: 137 boys and 127 girls aged 18.3 to 25.6 years) studied the dynamics of sociopsychological adaptation of students in the Metropolitan area. The majority of students (58\%) from XI'an had low indicators of socio-psychological adaptation, which was associated with high levels of situational and personal anxiety. High levels of aggression were also observed in this group. The assessment of social and psychological adaptation of Chinese students from Beijing also showed difficulties in adaptability and difficulties in psycho-emotional relations: almost half of the students (48\%) from Beijing took an intermediate position in terms of psychoemotional state. Interpersonal communication problems were identified in this group.Assessment of social and psychological adaptation of Chinese students from Harbin showed a fairly high level of adaptation in most students $(69 \%)$, which was expressed in a fairly good knowledge of the Russian language, intergroup communication, and low indicators of anxiety and aggression
\end{abstract}

\section{Introduction}

At present, significant processes of restructuring of all aspects of human existence are observed all over the world. This process also affects the issues of education in General and higher education in particular. Many developed countries seek to attract foreign applicants [1].

This is due to several reasons.

First, higher education brings quite high incomes. According to various expert estimates of experts in the field of education, the volume of the higher education market of the entire world community is approximately about $100-150$ billion us dollars. Russia takes less than $1 \%$ of this [2-5].

\footnotetext{
*Corresponding author: vg44@mail.ru
} 
Second, education has a powerful cultural impact on other countries.

Third, in our time, many people must constantly improve their scientific and professional level. Therefore, learning in a person's life is a permanent phenomenon.

Thus, Russia is also included in this process and one of the important directions in the country's foreign policy is cooperation in the field of education with other countries. In this regard, many leading Russian universities are making great efforts to attract foreign students. This area is currently one of the most important areas in educational activities. For example, according to the Ministry of Education and Science, the Peoples' Friendship University of Russia has students from about 158 countries, and the number of international students exceeds 9,000 [6].

Many foreign students are attracted to Russian higher education because of the relatively high quality of education and the relatively low price. At the same time, foreign students ' education in Russia may have adaptive difficulties, such as cultural and language difficulties, and climatic difficulties (cold winters, lack of sun exposure). All this can affect the work of psycho-functional systems and create difficulties in social and psychological adaptation [7-10].

Therefore, there is an urgent need to study the processes of adaptation of foreign students to improve in this direction. In this aspect, an integrated approach is important, which can systematically consider many environmental factors that can have a significant impact on the adaptation processes of Chinese students [11].

\section{Methods and object of research}

\subsection{Object of research}

To achieve this goal, we conducted a comprehensive survey and psychological testing of Chinese and Russian students. The total sample of the study was 264 practically healthy students (197 Chinese and 67 Russian students: 137 boys and 127 girls aged 18.3 to 25.6 years)

\subsection{Methods of research}

Psychological testing included the study of the psychoemotional sphere of the study sample and the frequency of assessment of the level of situational and personal anxiety (Spielberger-Hanin test). In addition, mental States (aggressiveness, frustration according to the Eysenck test) were studied. Expert assessments of teachers on special knowledge were given, and the level of knowledge of the General education level of Chinese students in specialized disciplines was determined. Mathematical data processing was done using the built-in Windows program (Excel).

\section{Results and discussion}

\subsection{Features of adaptation processes of Chinese students}

Our research of Chinese students from different regions revealed the following features.

First, the majority of Chinese students (89\%) compared to other students had sociocultural and language problems, which affected the psycho-emotional sphere. At the same time, a gender feature was also identified. Young men were more likely to experience anxiety. It was especially increased during the pre-examination period. 
The observation also revealed great difficulties for Chinese students in interpersonal and inter-group communication with other students from other countries.

The weakness of the Russian language among many Chinese students was also associated with constant communication in Chinese among themselves. Therefore, many Chinese students had poor communication only in the classroom and more often in Russian classes.

Against this background, a curious phenomenon can be noted often inflated self-esteem of many Chinese students, which contrasted with a weak level of motivational attitudes to the educational process, especially in language. Russian language skills (small vocabulary, difficulty in pronouncing Russian letters) and fear of making mistakes in the dialogue were the main reasons for this. Our observations are consistent with the data of N. R. Maksimov and D. S. Drozhzhin. [12,13].

\subsection{Dynamics of the psychoemotional state of Chinese students}

To identify the state of the psychoemotional sphere of Chinese students, we monitored anxiety, aggressiveness for 5 years.

Figure 1 shows the dynamics of situational anxiety in Chinese students.

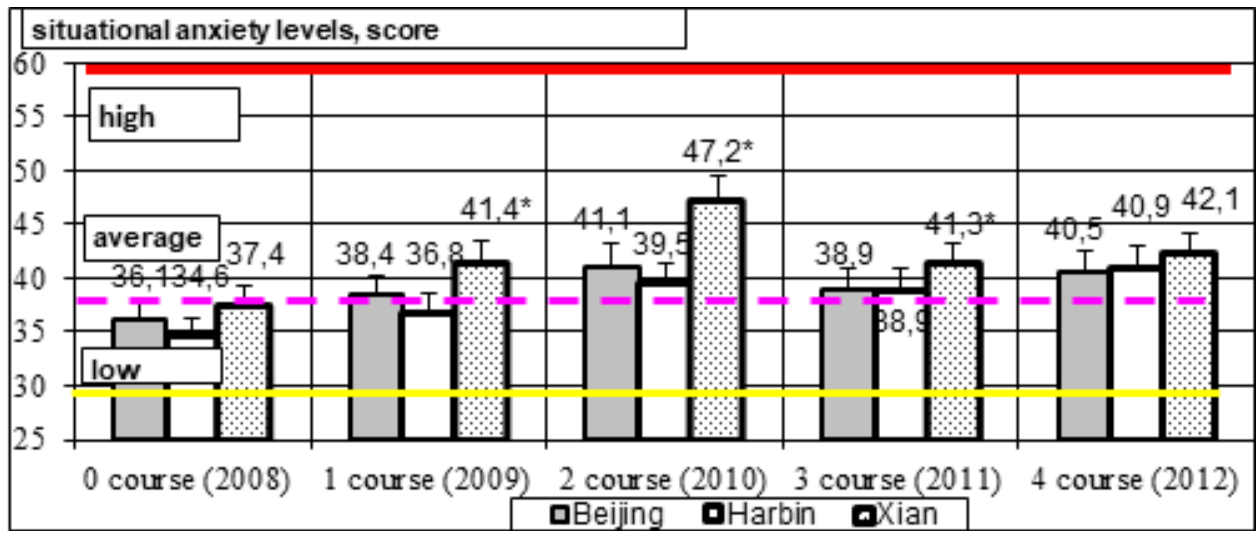

Fig. 1. Dynamics of average group indicators for situational anxiety of Chinese students $(n=197)$

Monitoring of anxiety showed the following dynamics. At the preparatory faculty, the indicators of situational anxiety in the three studied subgroups of students from Beijing,Harbin and XI'an did not differ significantly and were in the range of 36-37.4 points on the Spielberger test.

Further, there is an increase in situational anxiety among Chinese students from the course of the course, which reached its maximum values in the second year for students from Beijing (41.1 points) and XI'an (47.2 points) compared to students from Harbin (39.5) with a significant difference $(\mathrm{p}<0.05)$.

Testing in the 3rd year showed a decrease in the entire sample of Chinese students studied and some growth in the 4th year.

Aggressiveness.A longitudinal study of the aggressiveness of students from different regions of China showed the same trend, which revealed an increase in the level of aggressiveness in all three subgroups of Chinese students (Fig. 2.). 


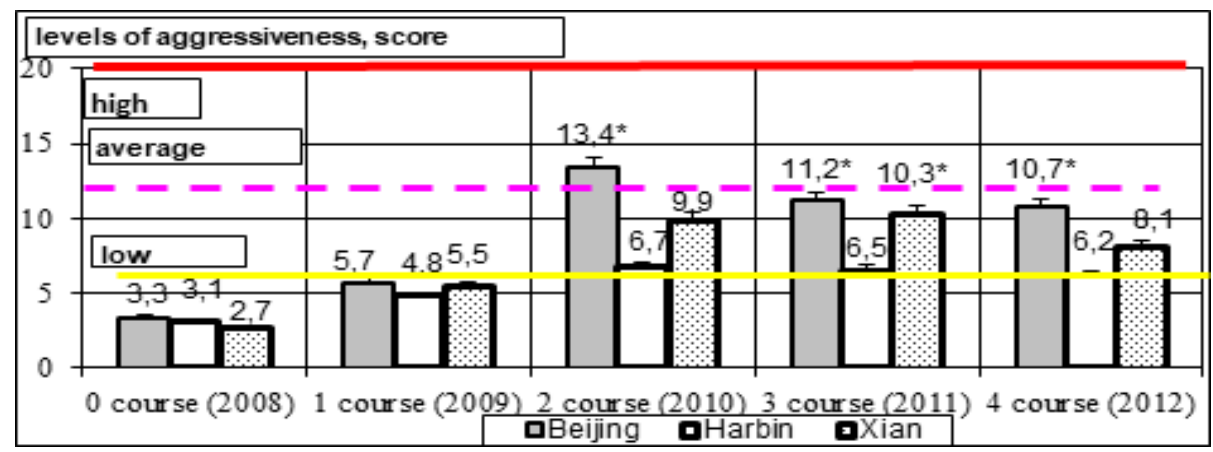

Fig. 2. Dynamics of average group indicators of aggressiveness of Chinese students $(n=197)$

At the initial stage (preparatory faculty) of education, the entire sample of Chinese students had a low level of aggressiveness. Then, as they continued their studies at the University, they found an increase in aggression indicators among Chinese students, which was highest in the second year for students from Beijing (13.4 points) and XI'an (9.9 points) and 6.7 points for students from Harbin.

The first and second years were marked by an increase in the level of aggression, especially among students from Beijing (from 5.7 to 13.4 points) and XI'an (from 5.5 to 9.9 points).

Further, in the third and fourth years, the sample of Chinese students showed a decline in the level of aggressiveness: Beijing-11.2 and 10.7 points, respectively; Harbin-6.5 and 6.2 points with a significant difference $(\mathrm{p}<0.05)$.

\section{Conclusions}

Thus, the assessment of social and psychological adaptation of Chinese students revealed different levels of adaptation processes.

1. The majority of students (58\%) from XI'an had low indicators of socio-psychological adaptation, which was associated with high levels of situational and personal anxiety. High levels of aggression were also observed in this group.

2. The assessment of social and psychological adaptation of Chinese students from Beijing also showed difficulties in adaptability and difficulties in psycho-emotional relations: almost half of the students (48\%) from Beijing took an intermediate position in terms of psycho-emotional state. Interpersonal communication problems were identified in this group.

3. The assessment of social and psychological adaptation of Chinese students from Harbin showed a fairly high level of adaptation in most students $(69 \%)$, which was expressed in a fairly good knowledge of the Russian language, intergroup communication and low indicators of anxiety and aggression

\section{Acknowledgements}

The publication has been prepared with the support of the "RUDN University Program 5-100".

\section{References}

1. V. V. Glebov, Journal Asia and Africa today, 12 (2013) 
2. V.V. Glebov, E.A. Soshnikov, Psychophysiological features and dynamics of adaptation processes of Chinese students in the Russian University (2018)

3. I.M. Vorob'eva, Foreign Students in a Russian University: Increasing Competition in Russian Education or a Forced Necessity, 10 (2015)

4. E.A. Soshnikov, E.V. Anikina, V.V. Glebov, Ecology: synthesis of natural science, technical and humanitarian knowledge materials of the III all-Russian scientific and practical forum and the I school of interecoprav (2012.)

5. T.E. Kuznetsova, Saint-Petersburg: Polytechnic University Publ., 1 (2010)

6. Official website of RUDN, www.rudn.ru

7. G.A. Mishin, Socio-Psychological Adaptation of Adolescents in The New Learning Environment, 18 (2016)

8. E.R. Shekunova, The XLII International Student Scientific-Practical Conference «Scientific Community of Students of The XXI Century. Social Science», 5 (2016)

9. M.V. Rostovtseva, Bulletin of Science and Education Development, 5 (2009)

10. L. Dittmer, Journal of Contemporary China, 28 (2010)

11. 11.D.M. Bertram, M. Poulakis, B. S. Elsasser, E. Kumar, Journal of Multicultural Counseling and Development, 42 (2014)

12. N. R. Maksimov, Scientific method.electron. Journal, 43 (2016)

13. D. S. Drozhzhina, https://universitas.hse.ru 